\title{
Fire Resistant Panels for the Tunnel Linings
}

\author{
Marina Gravit ${ }^{1}$, Sergey Antonov ${ }^{2}$, Oleg Nedryshkin ${ }^{1, *}$, Ekaterina Nedviga $^{1}$ and Valerii \\ Pershakov $^{3}$ \\ ${ }^{1}$ Peter the Great St. Petersburg Polytechnic University, 195251, Politekhnicheskaya st., 29, Russia \\ ${ }^{2}$ CEO LLC Prozasq, 107076, 42, Krasnobogatyrskaya st., Russia \\ ${ }^{3}$ National Aviation University of Ukraine, 03058, Kyiv st., 1, Ukraine
}

\begin{abstract}
Presents the results of studies of innovative materials in the field of experimental and theoretical research fire resistance fireproof panels Pyro-Safe Aestuver T. Owing to the assembly simplicity, materials cheapness, high ecological standard, recycling, reuse potential, are benefit. Research work is running to improve the knowledge about fireproof panels Pyro-Safe Aestuver T for tunnel lining, its basic performance, its long term behavior and in particular also its fire proof for example when used for the lining of road tunnels.
\end{abstract}

\section{Introduction}

Tunneling and transport tunnel construction has gained increasing importance both in Europe and internationally during the past 15 to 20 years. The vector of developments will continue in the future. The reason is provided by the results of a recently completed study by the Viennese Academy of Sciences.

This academy carried out an extensive survey on behalf of the Austrian Automobile and Touring Club on how tourist and goods traffic has developed in Europe. It reveals that private motoring in Europe will rise by around $40 \%$ by the year 2030 compared with 1997. Europe's highways will come ever closer to reaching their capacity in the near future thus introducing more stop than go for traffic than ever. Other surveys are no less pessimistic. The OECD (Organisation for Economic Co-operation and Development) for instance, reckons that by the year 2020, there will rise by around $50 \%$ compared with 1997 .

Nowadays around $10 \%$ of the urban population live in so-called mega cities with more than 15 million inhabitants. 26 mega cities distributed all over the globe, with no less than 18 of them located in Asia. The use of underground space will be required to a high degree to make sure that such mega cities and expansive urban regions in general are capable of functioning so that the quality of life is assured.

This applies to transport tunnels as well as to supply and disposal facilities and the storage of goods. In view of such developments, it is imperative that new logistics concepts, new ways to secure mobility and also new supplementary measures to improve the infrastructure are found. One solution is certainly to be found in exploiting the chances afforded by tunnelling pertaining to the overall securing of mobility, speeding up transportation processes and essentially for protecting the environment and countryside as

\footnotetext{
* Corresponding author: nedryshkin@gmail.com
} 
well [1].

The current and future major tunnel projects undoubtedly represent particular challenges in fire safety. During 2012 - 2014 in Russia (Sochi, North Ossetia) facing work in the tunnels have been carried out in a volume of $140000 \mathrm{~m}^{2}$ with fireproof panels Pyro-Safe Aestuver T [2].

Pyro-Safe Aestuver T - fireproof panels of glass fiber lightweight concrete to protect metal and concrete constructions, including for use in corrosive atmospheric conditions (eg, fireproof construction of refineries and chemical plants) and for underground traffic facilities (tunnels). Pyro-Safe Aestuver $\mathrm{T}-$ it is non-combustible, purely mineral, hydraulically-cemented, fireproof panels of glass fiber lightweight concrete.

Pyro-Safe Aestuver $\mathrm{T}$ has a dense and evenly distributed fiber structure through the entire cross-section of the panel. This method allows the production of thin panels with high ultimate tensile strength and compression in bending resistance and a high abrasion. Smooth, homogeneous and stable surface joint allow different possibilities of operation and handling.

Data on the characteristics of the boards listed in this table are not official information, and can be required from the Supplier [2].

In the paper [3] were investigated the strength and strain of high-strength concrete elements with confinement and steel fiber reinforcement including the conditions of the effect of elevated temperatures. In the paper [4] were investigated physical-mechanical properties of the modified fine-grained concrete subjected to thermal effects up to $200^{\circ} \mathrm{C}$.

The authors [5] conducted numerical analysis of thin steel panels loaded in shear at nonuniform elevated temperatures.

\section{Methods}

Testing experimental samples solid concrete plates with fireproof panels Pyro-Safe Aestuver T $15 \mathrm{~mm}$ and a density of $730 \mathrm{~kg} / \mathrm{m} \pm 10 \%$, were conducted to determine the fire resistance of the experimental samples submitted in accordance with [6]. The corresponding normative documents use for each type of material construction in the European Union [7 - 15].

\section{Experiment}

Identification of experimental samples. In the research were test two solid concrete panels with fireproof panels Pyro-Safe Aestuver T $15 \mathrm{~mm}$ and a density of $730 \mathrm{~kg} / \mathrm{m}^{2} \pm 10 \%$. Experimental samples sizes $4200 \times 2000 \times 140 \mathrm{~mm}$ plates were made of heavy concrete class B 22.5 , an average density of $2400 \mathrm{~kg} / \mathrm{m}^{3}$.

The thickness of the protective layer of concrete to the center of gravity of the working reinforcement from the bottom (heated) side was $20 \mathrm{~mm}$. Installation of fire-retardant panels Pyro-Safe Aestuver T $15 \mathrm{~mm}$ and a density of $730 \mathrm{~kg} / \mathrm{m} \pm 10 \%$ was carried out on the bottom (heated) surface experimental samples concrete solid plates using self-tapping screws for concrete in accordance with the technical requirements.

Test conditions. Date of first experience - 09/17/2015, 24/09/2015; second 24/09/2015. Ambient temperature during the first experience $-18 \mathrm{C}^{\mathrm{o}}$; second $-20 \mathrm{C}^{\mathrm{o}}$. Relative air humidity of first experience $-48 \%$; second $-50 \%$.

Air flow rate of first and second experience is not more than $0.5 \mathrm{~m} / \mathrm{s}$. Figure 1 shows prepared for testing experimental sample No 1 appended to the uniformly distributed load. 


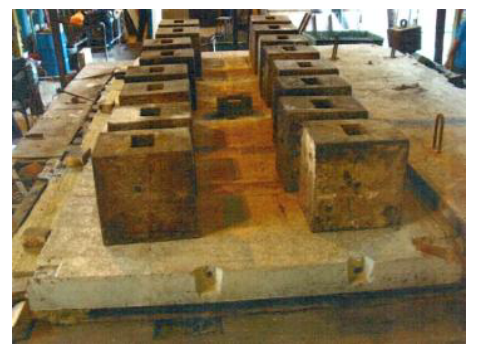

Fig. 1. Experimental sample number 1 appended to the uniformly distributed load

The experimental samples were installed on the experimental set-up and subjected to subject thermal effects on a standard temperature conditions.

The test of fireproof panels was conducted under a constant uniformly distributed load equal to $7.9 \mathrm{kPa}\left(800 \mathrm{~kg} / \mathrm{m}^{2}\right)$, without taking into account its own weight of the experimental sample. The magnitude of the load determined in accordance with the technical requirements of the customer. Pressing experimental samples carried iron weights weighing $25 \mathrm{~kg}$ and $330 \mathrm{kgs}$, which are placed evenly on the unexposed surface of the concrete plates. Experienced concrete plates experimental sample according to customer's specifications were 2-sided bearing on the hinged point and hinged point - movable support. The distance from the panels to the ends of the rocker bearings was $100 \mathrm{~mm}$.

Thus, a working experimental sample span reinforced concrete floor plates is $4000 \mathrm{~mm}$. Deflections of experimental samples in the middle span, during loading and during the test was measured by MP-3 deflectometer. Deflection panels after loading was at 1-st experimental sample of $30.0 \mathrm{~mm}$ in the 2 -nd $-27.8 \mathrm{~mm}$.

The temperature in the furnace fire chamber furnace was measured by thermocouples, uniformly distributed along the length of the experimental sample in six locations, and test experimental samples temperature was measured by thermocouples type TCA established in the amount of 5 pieces at the non-heated surface of the experimental sample. Figure 2 shows arrangement of fireproof panels Pyro-Safe Aestuver T to the concrete construction.

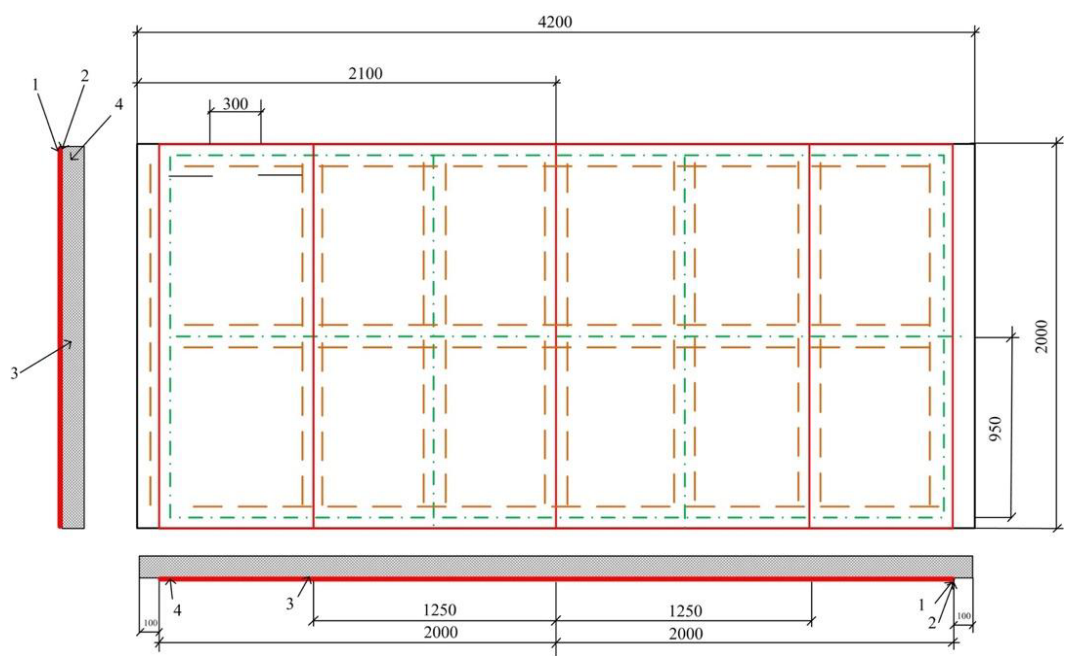

Fig. 2. Arrangement of fireproof panels Pyro-Safe Aestuver $\mathrm{T}$ to the concrete construction; 1 - fireproof panels Pyro-Safe Aestuver T; 2 - band of panels Pyro-Safe Aestuver T; 3 concrete screw TSM-80 5x40 mm; 4 - concrete screw TSM-80 6x60 mm. 


\section{Results}

The curves of temperatures and deflections experienced plates experimental samples with fireproof panels Pyro-Safe Aestuver T are shown in figure 3.

While testing experimental plate samples with fireproof panels Pyro-Safe Aestuver T, the following characteristics of samples behavior were observed:

a. 90 - 95 minutes - the appearance of surface cracks in the fireproof panels, and their gradual disclosure;

b. $110-115$ minutes - there is a partial collapse of fireproof panels.

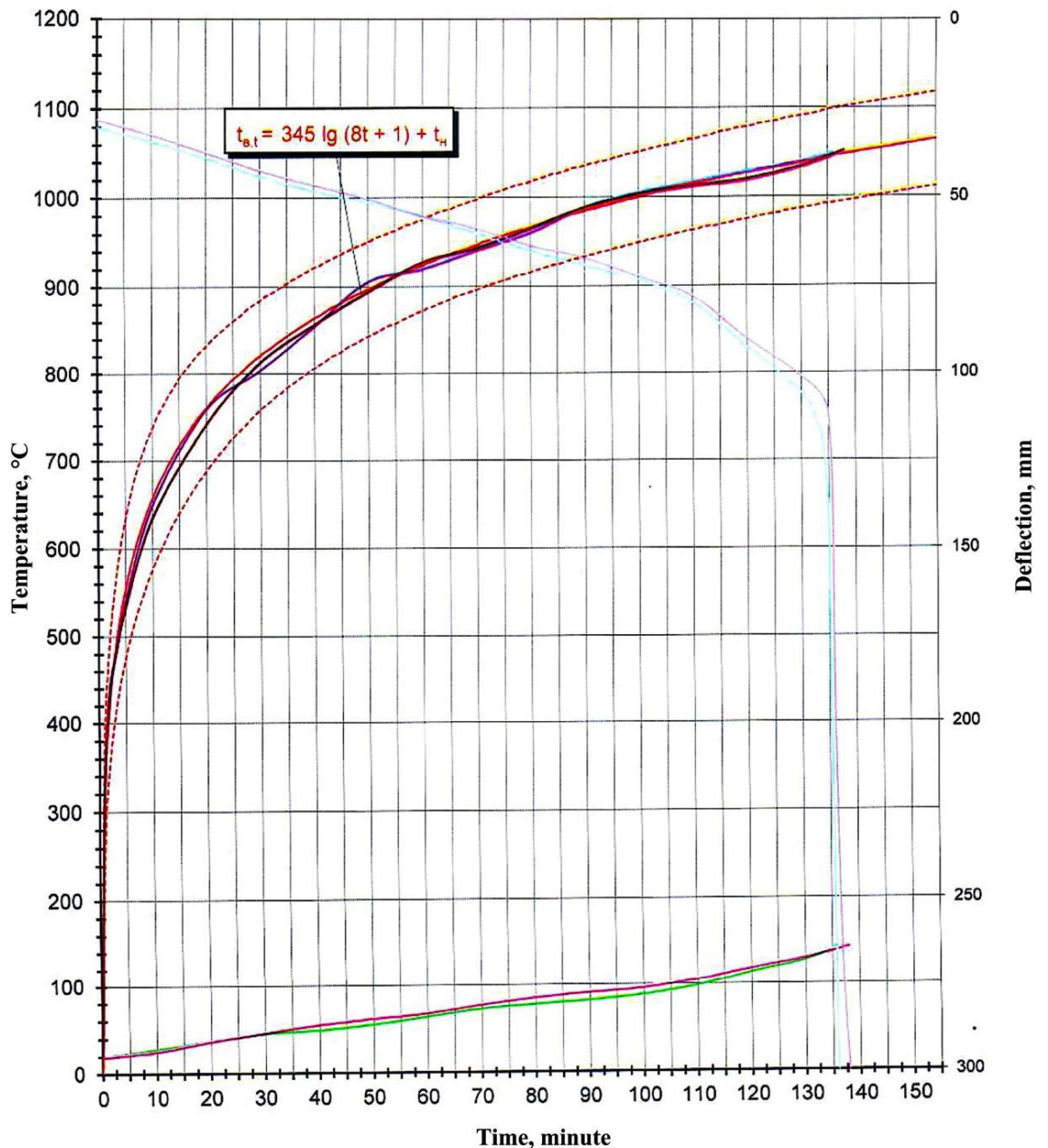

Time, minute

\footnotetext{
- time, temp., standard temperature curve;

------ upper and lower permissible limits of deviation from time, temp.;

- the average air temperature in the furnace fire chamber, experience No 1 (sample No 1);

- the average air temperature in the furnace fire chamber, experience No 2 (sample No 2);

- the average temperature on the unexposed surface of the floor plate (sample No 1);

- the average temperature on the unexposed surface of the floor plate (sample No 2); deflection at mid-span reinforced concrete floor plate (sample No 1); deflection at mid-span reinforced concrete floor plate (sample No 2).
}

Fig. 3. Curves of temperature changes and growth troughs, experimental samples. 


\section{Discussion}

At the 136th minute of the first test and at the 138th minute of the second test, experimental samples cross over in limiting condition characterized by a rapid increase in the bend and subsequent collapse of the experimental samples (refer with: Fig. 4).

As a result of the progressive achievement of the strain growth rate of fire resistance experimental samples loss of load-bearing structure ability $(\mathrm{R})$ was detected at the 136th and at 138th minutes of the test (1st and 2 nd experimental samples, respectively) more than $1.19 \mathrm{~cm} / \mathrm{min}$, the limit deflection of more than $200 \mathrm{~mm}$, and the subsequent collapse of the experimental samples. At the time of achievement of experimental samples, a limiting condition for the loss of bearing capacity of the structure $(\mathrm{R})$, the average temperature on the unexposed surface was 143 and $145^{\circ} \mathrm{C}$, for 1 st and 2 nd of the experimental samples, respectively. Temperature rise of the unexposed surface of the experimental samples overlap in one of the monitored points in comparison with the temperature before the test by more than $180^{\circ} \mathrm{C}$ at the time of the collapse of the samples have been recorded. At the time of the collapse of experimental samples, through the formation of cracks or holes through which to penetrate the surface of the unexposed products of combustion or flames, not fixed.

In the paper [18] provides a review of the criteria that are normally employed in assessing the risk and consequences of fires in tunnels, and the selection of suitable timetemperature curves that describe the evolution of worst-case fires. The advantages and drawbacks of alternative fire protection methods, including sprayed-on fire protection materials, cementitious linings and the addition of polypropylene fibres, are briefly outlined. Effective passive fire protection can be provided by proprietary fireproof panels. The panels have good insulation properties and can withstand temperatures exceeding 1350 ${ }^{\circ} \mathrm{C}$. They can be designed such that the temperatures at the face of the structural lining do not exceed $350{ }^{\circ} \mathrm{C}$, which will prevent spalling and any changes in the mechanical properties of the concrete. The required panel thicknesses vary between 20 and $30 \mathrm{~mm}$ depending on the temperature development over time.

The paper [19] author reports that the majority of existing tunnels worldwide rely wholly on active systems to ensure tunnel fire safety.

Passive fire protection is designed to be installed as a shield to protect the structure from fire at any time. They are not reliant on any initiation system as with active systems, and they always work. They maintain ventilation systems that are separated from the traffic by internal concrete structures, and also protect against catastrophic damage to third party property and life by preventing tunnels from collapsing.

Currently in Europe, both active and passive systems employed together are seen to be necessary for new tunnels in the future.

Pre-fabricated fire protection panels offer a clear advantage for box shaped tunnels where there are no curved tunnel walls or complex geometries. However, they are not well suited to curved profile tunnels and are generally 1.5 to 2 times more expensive than sprayed systems, which can prove cost prohibitive. The samples used in our work in the tunnels with a curved profile and have a concurrency price that makes fireproof panels Pyro-Safe Aestuver T the right solution in the field of fire safety [18 - 27]. 


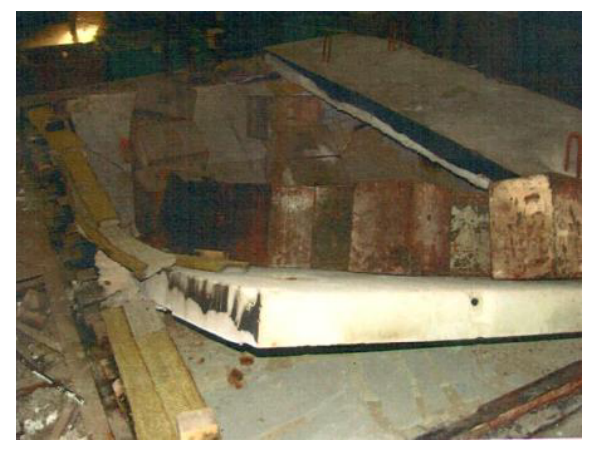

Fig. 4. The experimental sample No 2 after the test.

\section{Conclusion}

The tragic fire accidents during the last years led to strong discussions in professional circles all over Europe and all over the world as well [20].

In the ongoing test concrete plates with fireproof panels Pyro-Safe Aestuver T $15 \mathrm{~mm}$ and a density of $730 \mathrm{~kg} / \mathrm{m}^{3} \pm 10 \%$, tested under constant uniformly distributed load equal $7.9 \mathrm{kPa}\left(800 \mathrm{~kg} / \mathrm{m}^{2}\right)$, without taking into account its own weight plate at 137 minutes, which corresponds to the classification of REI 120 [6].

Achieved the results of studies of innovative materials in the field of experimental and theoretical research fire resistance fireproof panels Pyro-Safe Aestuver T confirm the high quality of the present samples. The provision of passive fire protection to tunnels is not usually required, if the fire loads are low and the safety provisions are specified and maintained to a high standard. However, the existence of imported fire risks such as vehicle shuttles and fuel tank may imply significantly higher fire loads. In addition, there may be cases where the collapse of a tunnel may imply unacceptably high social costs. In such cases, a cost/benefit analysis, informed by a quantitative risk assessment, may demonstrate a strong case for additional fire protection measures, including passive fire protection and/or fire suppression systems as fireproof panels.

\section{References}

1 Haack, Innovations in Underground Construction and Tunnelling; special issue Tunnel, (2004)

2 Information on http://www.stalprotect.ru/pyro-safe_aestuver_t_tonnelnaya1

3 V. Korsun, N. Vatin, A. Franchi, A. Korsun, P. Crespi, S. Mashtaler, Procedia Engineering, 117(1), 970-979 (2015)

4 V. Korsun, N. Vatin, A. Korsun, D. Nemova, AMM, 633-634, 1013-1017 (2014)

5 M. Salminen, M. Heinisuo, Journal of Constructional Steel Research, 97, 105-113 (2014)

6 ISO 834-1:1999 Fire-resistance tests - Elements of building construction - Part 1: General requirements.

7 T. Eremina, M. Gravit, Y. Dmitrieva, Architecture and Construction of Russia, 8, 24 29 (2012)

8 BS EN 13501-2:2007+A1:2009. Fire classification of construction products and building elements. Part 2: Classification using data from fire resistance tests, excluding ventilation services.

9 Information on http://www.eota.eu/en-GB/content/etags-used-as-ead/26/ 
10 ENV 13381-3:2002. Test methods for determining the contribution to the fire resistance of structural members - Part 3: Applied protection to concrete members.

11 BS EN 13381-4:2013. Test methods for determining the contribution to the fire resistance of structural members - Part 4: Applied protection to steel members.

12 ENV 13381-5:2014. Test methods for determining the contribution to the fire resistance of structural members - Part 5: Applied protection to concrete/profiled sheet steel composite members.

13 EN 13381-6:2008. Test methods for determining the contribution to the fire resistance of structural members. Part 6. Applied protection to concrete filled hollow steel columns.

14 ENV 13381-7:2002 Test methods for determining the contribution to the fire resistance of structural members - Part 7: Applied protection to timber members.

15 EN 13381-8:2013 Test methods for determining the contribution to the fire resistance of structural members - Part 8: Applied protection.

16 F. Tarada, M. King, Structural fire protection of railway tunnels.

17 F. Clement, Fire protection options for concrete tunnel linings, Fourth International Symposium on Tunnel Safety and Security, Frankfurt am Main, Germany, March 1719, 2010.

18 A. Haack, Tunnelling and Underground Space Technology, 17, 117-127 (2002)

19 Ahmad, S. Hassan, A. Ripin, M. Ali, S. Haron, Fire Safety Journal, 58, 160-169 (2013)

20 S. Chang, S. Choi, J. Lee, Original Research Article Tunneling and Underground Space Technology, 54, 1-12 (2016)

21 N. Bezgin, Construction and Building Materials, 95, 279-286 (2015)

22 H. Ingason, Y. Li, A. Lonnermark, Tunnelling and Underground Space Technology, 43, 327-335 (2014)

23 H.Lai, S.Wang, Y. Xie, Tunnelling and Underground Space Technology, 35, 122-134 (2013)

24 S. Choi, J. Lee, S. Chang, Procedia Engineering, 62, 907-915 (2013)

25 Z. Yuan, B. Lei, A. Kashef, Construction and Building Materials, 24, 1984-1994 (2010)

26 J. Ćetković, M. Knežević, M., Žarković, V. Murgul, N. Vatin, AMM, 638-640, 24652470 (2014)

27 M. Lazarevska, M. Cvetkovska, M, Knezevic, V. Murgul, N. Vatin, AMM, 627, 276282 (2014) 